\title{
DENERVAÇÃO ARTICULAR COXOFEMORAL EM CÃES COM DOENÇA ARTICULAR DEGENERATIVA SECUNDÁRIA À DISPLASIA
}

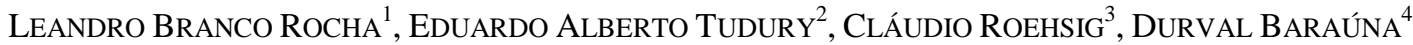 \\ RiCARDO CHIORATTO ${ }^{5}$, FELIPE PURCELl ARAÚJO ${ }^{6}$, BERNADO KEMPER ${ }^{7}$

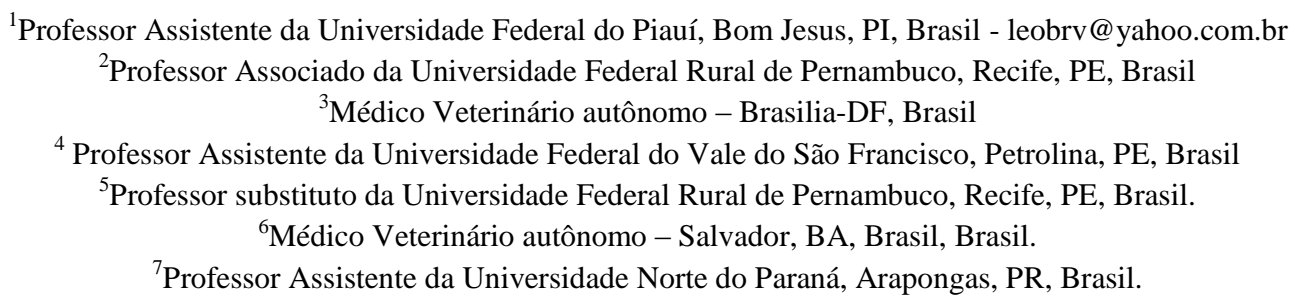

\section{RESUMO}

A técnica de denervação coxofemoral é realizada em cães displásicos, com o intuito de aliviar a dor. O objetivo deste trabalho foi avaliar alívio da dor, melhora da função articular, reabilitação muscular e progressão da instabilidade em 10 cães displásicos submetidos à técnica de denervação da articulação coxofemoral. A graduação da apresentação clínica foi realizada através de avaliações específicas da andadura, testes de estação bípede, de rotação com abdução externa e de iliopsoas. A reabilitação muscular foi avaliada através da circunferência da coxa e exame físico. A avaliação da instabilidade foi feita através de técnica radiográfica para índice de distração. $\mathrm{Na}$ graduação da claudicação e teste de estação bípede foi verificado que houve redução significante a partir de um mês pós-cirúrgico. Já nos testes de abdução com rotação externa, houve redução da dor a partir do sétimo dia póscirúrgico; no teste de iliopsoas houve redução significante da dor, em todos os tempos do pós-cirúrgico. Houve aumento significante da circunferência da coxa a partir do sétimo dia. Foi observado que $90 \%$ tiveram redução do índice de distração, refletindo melhora da instabilidade. A técnica é eficaz no alívio da dor, na reabilitação muscular após a melhora na capacidade de exercitar-se e na redução da instabilidade, sendo motivo de satisfação para os proprietários.

PALAVRAS-CHAVE: denervação; displasia; dor; reabilitação muscular.

\section{JOINT HIP DENERVATION IN DOGS WITH DEGENERATIVE JOINT DISEASE SECONDARY TO DYSPLASIA}

\section{ABSTRACT}

The hip denervation technique has been performed in dysplasic dogs, demonstrating to be efficient in the relief of pain. The objective of this work was to evaluate pain relief, improvement of joint function, muscular rehabilitation and instability progression in 10 dysplasic dogs submitted to the hip joint denervation technique. The grading of the clinical presentation was performed according to specific evaluation of walking, biped station, rotation with external abduction, subluxation and iliopsoas. The muscular rehabilitation was evaluated through the circumference of the thigh and physical examination. The instability was evaluated through the values of distraction index (DI). In the claudication graduation and the biped station test, we verified that there was a significant reduction after one month post-surgery. In the abduction with external rotation tests, there was a 
reduction in pain after the seventh day; in the iliopsoas test there was a significant reduction in pain in all the post-surgery times. There was a significant increase in thigh circumference after the seventh day. We observed that $90 \%$ of the articulations had a reduction in their DI, reflecting an improvement of their instability. The technique is efficient in the relief of pain, muscular rehabilitation after the improvement of the ability to exercise, and in reduction of instability, being the cause of owner satisfaction.

KEYWORDS: denervation; dysplasia; muscular rehabilitation; pain.

\section{INTRODUÇÃO}

A displasia coxofemoral é caracterizada pelo desenvolvimento ou crescimento anormal da articulação coxofemoral, em geral bilateral (93\%), o que pode evoluir para doença articular degenerativa (DAD). É uma afecção comum em cães, prevalente em raças de grande porte (THOMAS et al., 1992; RISER, 1993; ARAUJO et al., 1997; MARTINEZ, 1997; TORRES et al., 1999).

Os proprietários dos animais displásicos relatam uma história de claudicação progressiva e crônica. A maioria apresenta marcha bamboleante, rígida, curta e relutam em fazer exercícios. Os sinais podem ter piora aguda após aumento da atividade física (HAAN \& BEALE, 1999; PIERMATTEI \& FLO, 1999). Quando o animal convive muito tempo com a dor e a DAD está presente, a musculatura da região pélvica e da coxa normalmente atrofia-se, principalmente os músculos glúteos e quadríceps (THOMAS, 1992; RISER, 1993; SOMMER \& FRATOCCHI, 1998; PIERMATTEI \& FLO, 1999; NOGUEIRA \& TUDURY, 2002).

Existem vários testes específicos para avaliar a função e a dor na articulação coxofemoral, dentre eles: avaliação da claudicação, testes de estação bípede, de abdução com rotação externa e do iliopsoas (MARTINEZ, 1997; SOMMER \& FRATOCCHI, 1998; PIERMATTEI \& FLO, 1999; NOGUEIRA \& TUDURY, 2002). Cães displásicos podem exibir dor, demonstrando o desconforto através de tensão muscular, flexão brusca do membro ou até mesmo vocalização e agressão (THOMAS et al., 1992; WENDELBURG, 1998).

Uma vez diagnosticada, as alterações patológicas da displasia são geralmente irreversíveis. Nenhum tratamento é efetivo em restaurar uma articulação displásica à normalidade (BIASI et al., 2000; COOK, 2003).

Os benefícios do tratamento clínico quando a doença já está avançada normalmente são temporários, sendo necessário realizar técnicas cirúrgicas que promovem o alívio da dor, dentre elas, a denervação da articulação coxofemoral
(KÜPPER \& KINZEL， 1994; KINZEL \& KÜPPER, 1997; KINZEL et al., 2002a, b; BRAUN et al., 2003).

KÜPPER \& KINZEL (1994), na Alemanha, estudando a técnica de artroplastia da borda acetabular dorsal, verificaram que os cães submetidos a essa técnica apresentavam um surpreendente alívio da dor logo nos primeiros cinco a 10 dias após a cirurgia e concluíram que esse alívio é causado pela eliminação dos ramos que inervam a cápsula nessa região. Sendo assim, desenvolveram uma técnica de denervação capsular para alívio da dor em cães displásicos.

A modalidade sensorial dor está associada, entre outros fatores, às terminações nervosas que ocorrem nos revestimentos fibrosos dos ossos, como periósteo e cápsula articular fibrosa (GARDNER, 1950). A dor que os animais displásicos sentem, aparentemente, tem várias origens, dentre elas: estiramento e inflamação da cápsula articular, contratura dos músculos adutores da articulação coxofemoral, provocando processos neuroirritativos nas inserções destes, e alongamento e sensibilização do periósteo, devido à formação de osteófitos (HAMLET et al., 1972; ARNOCZKY \& MARSHALL, 1981; BANKS, 1992; GASSE et al., 1996; MORGAN, 1997; PIERMATTEI \& FLO, 1999; ALVAREZ, 2001; KINZEL et al., 2002b).

A cápsula articular coxofemoral canina recebe maior tensão na região crânio-lateral, por isso é a região com maior número de receptores da dor. Dessa forma, a inervação sensitiva da porção caudal-lateral e ventral contribui minimamente para a sensação de dor em casos de displasia coxofemoral (KINZEL et al., 1998; KINZEL et al., 2002a, b).

A cápsula da articulação coxofemoral em cães é enervada na sua porção crânio-lateral por ramos do nervo glúteo cranial, na porção caudolateral por ramos do nervo ciático, na porção crânio-medial por ramos do nervo femoral e na porção caudo-medial por ramos do nervo obturatório (GASSE et al., 1996; KINZEL et al., 1998; KINZEL et al., 2002a, b). Todos esses ramos percorrem inicialmente o periósteo do corpo do ílio antes de atingir a cápsula articular (GASSE et al., 
1996; KINZEL et al., 1998; KINZEL et al., 2002b). A técnica de denervação craniolateral da articulação coxofemoral em cães displásicos com DAD faz com que os animais sintam-se mais confortáveis devido ao alívio da dor e ao retorno da função articular e dos membros, abolindo a necessidade de medicamentos analgésicos. Isso favorece o condicionamento físico da musculatura da bacia e coxa, fortalecendo a articulação displásica incongruente. As lesões articulares causadas pela displasia e sua evolução permanecem inalteradas (KÜPPER \& KINZEL, 1994; GASSE et al., 1996; KINZEL \& KÜPPER, 1997; KINZEL et al., 2002a, b; BRAUN et al., 2003).

O grau de atrofia muscular no préoperatório é indicador para o sucesso no pósoperatório. Quanto maior a atrofia muscular do membro atingido, maior o tempo para melhora (BRAUN et al., 2003).

$\mathrm{Na}$ literatura, são relatadas diferentes técnicas de denervação da caspula articular, diferenciando-se principalmente em sua abordagem cirúrgica, que pode ser aberta ou fechada. Em todas as técnicas, relata-se sucesso no alívio da dor variando de 90,6\% a 96\% (KINZEL \& KÜPPER, 1997; KINZEL et al., 2002a, b; BRAUN et al., 2003; FERRIGNO et al., 2007a; SELMI et al., 2009; MINTO et al., 2012; ANDERSON, 2011; SILVA et al., 2012).

Já na primeira semana de pós-operatório, observa-se alívio da dor (FERRIGNO et al., 2007a). Alguns pacientes foram avaliados durante 10 anos no período pós-operatório e permaneceram livres de dor nesse tempo (KINZEL et al. 2002b). Porém, BRAUN et al. (2003) verificaram recidiva da dor em 32,6\%, num período de 3,5 anos de avaliação; contudo, mesmo nesses casos, os proprietários classificaram os resultados como satisfatórios. Animais mais jovens, abaixo de um ano de idade, apresentaram melhores resultados do que os com maior idade, entre 7 e 8 anos.

Este trabalho teve como objetivo avaliar o alívio da dor, a melhora da função articular, a reabilitação muscular e a progressão da instabilidade, em cães displásicos com DAD, submetidos à técnica de denervação da articulação coxofemoral.

\section{MATERIAL E MÉTODOS}

Para o estudo, foram utilizados 10 cães, com diagnóstico de DAD secundária à displasia coxofemoral. Quatro Rottweilers e seis Pastores Alemães; sete cães com idade variando de seis meses a um ano e quatro meses, e três cães com idade entre cinco e nove anos. O peso variou de 18 a $37 \mathrm{~kg}$.

Após o exame clínico, realizou-se exame ortopédico geral para detectar alterações dolorosas em todas as articulações e meticulosamente nas articulações coxofemorais. Especificamente neste trabalho, criaram-se escalas (Quadro 1) para avaliação da função e dor articular por meio dos testes de estação bípede, andadura, abdução com rotação externa e iliopsoas.

Quadro 1: Escores dos testes específicos utilizados para avaliação da função e dor articular dos cães submetidos à técnica de denervação. Recife-PE, 2005

\begin{tabular}{|c|c|c|c|}
\hline \multirow{2}{*}{ Escores } & \multicolumn{3}{|c|}{ Testes } \\
\hline & Estação bípede & Andadura & Abdução com rotação externa \\
\hline 0 & Sem alteração & Sem alteração & Sem queixas \\
\hline 1 & $\begin{array}{l}\text { Permanece na posição } \\
\text { com discreta flexão } \\
\text { do quadril e costas }\end{array}$ & $\begin{array}{l}\text { Claudicação discreta com } \\
\text { apenas passos curtos }\end{array}$ & $\begin{array}{l}\text { Discreto movimento da cabeça e flexão do } \\
\text { membro }\end{array}$ \\
\hline 2 & $\begin{array}{l}\text { Flexão do quadril e } \\
\text { costas tentando descer }\end{array}$ & $\begin{array}{c}\text { Claudicação moderada com } \\
\text { passos curtos, ocasional não } \\
\text { sustentação do membro, e } \\
\text { cabeca levantada }\end{array}$ & $\begin{array}{l}\text { Levanta a cabeça e/ou chora, flexão do } \\
\text { membro, mas não há dificuldade de } \\
\text { imobilização do cão na mesa }\end{array}$ \\
\hline 3 & $\begin{array}{l}\text { Incapaz de iniciar o } \\
\text { posicionamento }\end{array}$ & $\begin{array}{l}\text { Claudicação grave com a } \\
\text { cabeça abaixada e não } \\
\text { consegue dar muitos passos }\end{array}$ & $\begin{array}{l}\text { Tenta levantar-se e chora ou demonstra } \\
\text { agressão, flexão do membro, tensão } \\
\text { muscular com dificuldade de imobilização } \\
\text { do cão na mesa }\end{array}$ \\
\hline
\end{tabular}


$\mathrm{O}$ volume da massa muscular foi considerado, medindo-se a circunferência da coxa, com o auxílio de uma fita métrica no ponto médio entre o trocanter maior e a borda proximal da patela, para avaliação da musculatura da coxa, nos tempos pré-cirúrgico, 48 horas, sete dias, um mês, dois, quatro e seis meses.

A confirmação radiográfica da displasia coxofemoral, com verificação da $\mathrm{DAD}$ e grau de instabilidade, foi feita com o animal anestesiado e utilizando-se o posicionamento da técnica PennHip ${ }^{\circledR}$, determinando-se os valores do índice de distração (ID) e do NorDis (ADAMS et al., 1998).

No dia da cirurgia, os animais foram encaminhados à sala de preparo cirúrgico onde foi aplicado antibiótico profilático cefalotina ${ }^{1}$ $(25 \mathrm{mg} / \mathrm{kg} / \mathrm{IV})$, flunixin meglumine ${ }^{2}(1 \mathrm{mg} / \mathrm{kg} / \mathrm{SC}) \mathrm{e}$ realizada tricotomia da área a ser operada. Em seguida, aplicou-se a pré-anestesia com diazepam ${ }^{3}$ $(0,5 \mathrm{mg} / \mathrm{kg} / \mathrm{IV})$ e acepromazina ${ }^{4}(0,05 \mathrm{mg} / \mathrm{kg} / \mathrm{IM})$. A medicação para indução anestésica foi administrada na sala de cirurgia e dependeu das condições clínicas do paciente (thiopental sódico ${ }^{5}-12,5 \mathrm{mg} / \mathrm{kg} / \mathrm{IV}$, quetamina $^{6}-12,5 \mathrm{mg} / \mathrm{kg} / \mathrm{IM}$ ou propofol ${ }^{7} 4$ $\mathrm{mg} / \mathrm{kg} / \mathrm{IV})$. Para anestesia epidural, injetou-se bupivacaina $^{8}(1 \mathrm{mg} / \mathrm{kg})$ no espaço vertebral $\mathrm{L}_{7}-\mathrm{S}_{1}$. A manutenção anestésica foi feita com halotano ${ }^{9}$ ou isoflurano ${ }^{10}$ dependendo da condição orgânica e cardiovascular de cada cão.

A abordagem cirúrgica à articulação coxofemoral, conforme descrição de KINZEL et al. (2002b), compreendeu incisão cutânea de 3 a 5 cm de comprimento, iniciando-se na região cranial do trocanter maior e progredindo em direção à crista ilíaca. Nessa área foram abordados os músculos

\footnotetext{
${ }^{1}$ Cefalotina sódica $1 \mathrm{~g}$, Instituto BioChimico Ltda, Rua Antônio João no 218, Cordovil, Rio de Janeiro-RJ.

${ }_{2}$ Banamine $10 \mathrm{mg}$. Schering-Plough Veterinária - Indústria Química Farmacêutica Schering-Plough S.A. Rua Antônio da Chagas, 1623, 2oㅡㄴ andar. São Paulo-SP

${ }^{3}$ Diazepam $5 \mathrm{mg} / 1 \mathrm{ml}$. Sigma Farma. Nature's Plus Farm. Ltda. Rodovia SP-101, km 08. Hortolândia-SP

${ }^{4}$ Acepran 0,2\% e 1\% - Univet S.A. Indústria Veterinária. Rua Climaco Barbosa, 700. São Paulo-SP.

5 Thiopentax 1g, Cristalia - Produtos Químicos Farmacêuticos Ltda., Rodovia Itapira - Lindóia, km 14, Itapira-SP.

${ }^{6}$ Dopalen 10\%. Laboratórios Calier do Brasil Ltda. Av. Manoel Pedro Pimentel, 15. Osasco-SP

${ }^{7}$ Diprivan 1\%. AstraZeneca do Brasil Ltda.. Rodovia Raposo Tavares, km 26,9. Cotia Moinho Velho-SP.

${ }^{8}$ Marcaína 0,5\%. AstraZeneca do Brasil Ltda.. Rodovia Raposo Tavares, km 26,9. Cotia Moinho Velho-SP.

${ }^{9}$ Halothano. Cristália Produtos Químicos Farmacêuticos Ltda. Av. Paoletti, 363. Itapira-SP

${ }^{10}$ Forane. Abbott Laboratórios do Brasil Ltda. Rua Michigan, 735. São Paulo-SP
}

bíceps femoral, glúteo médio e o tensor da fascia lata, os quais foram divulsionados através do triângulo existente entre eles. Um retrator de Hohmann foi inserido ventralmente aos músculos glúteos médio e profundo, apoiando-se na margem dorsal do ílio, cranial à espinha ilíaca, elevando-se e afastando dorsalmente esses músculos com um movimento de alavanca. Assim, ficou exposta e visível a área a ser denervada no corpo do osso ílio, crâniolateralmente à cápsula articular coxofemoral (Figura 1-A).

A denervação foi realizada eliminando-se o periósteo da superfície cortical do osso ílio, debridando e raspando, com um elevador de periósteo, uma área em forma de meia-lua situada entre a margem crânio-dorsal da cápsula articular, até a margem ventral do ílio, estendendo-se também a manobra, ao redor das áreas de inserções musculares ilíacas dos músculos reto femoral e glúteo profundo (Figura 1-B).

Após a lavagem dos tecidos com soro fisiológico, realizou-se oclusão da ferida cirúrgica em três planos: fascia muscular, tecido subcutâneo e pele, utilizando-se para tal, fio de náilon agulhado, com padrão de sutura contínuo festonada, continuo simples e isolado simples respectivamente.

Após o retorno anestésico, foi receitado curativo na ferida cirúrgica com digluconato de clorexidina (uma vez ao dia), cobertura com gaze estéril e esparadrapo micropore, antibiótico cefalexina ( $25 \mathrm{mg} / \mathrm{kg} / \mathrm{TID}$ - completando 24 horas) e antiinflamatório flunixin meglumine $(1,0 \mathrm{mg} / \mathrm{kg} / \mathrm{SID}$ - durante 2 dias).

Para verificação da eficácia da técnica no alívio da dor, no retorno da função e na reabilitação muscular, as mesmas avaliações realizadas no précirúrgico, foram repetidas 48 horas, sete dias, um, dois, quatro, e seis meses após a cirurgia.

A progressão da DAD e a lassidão articular foram avaliadas nos tempos pré-operatório e após seis meses, comparando-se as imagens radiográficas obtidas pela técnica PennHip ${ }^{\circledR}$ (índice de distração) incluindo NorDis.

O teste não paramétrico de Wilcoxon para diferenças entre pares ordenados foi utilizado para comparação dos resultados dos tempos préoperatório e pós-operatórios. As amplitudes da melhora das graduações foram calculadas subtraindo a graduação pré-cirúrgica pela que foi estabelecida nos tempos pós-operatórios (REIS, 2003). 


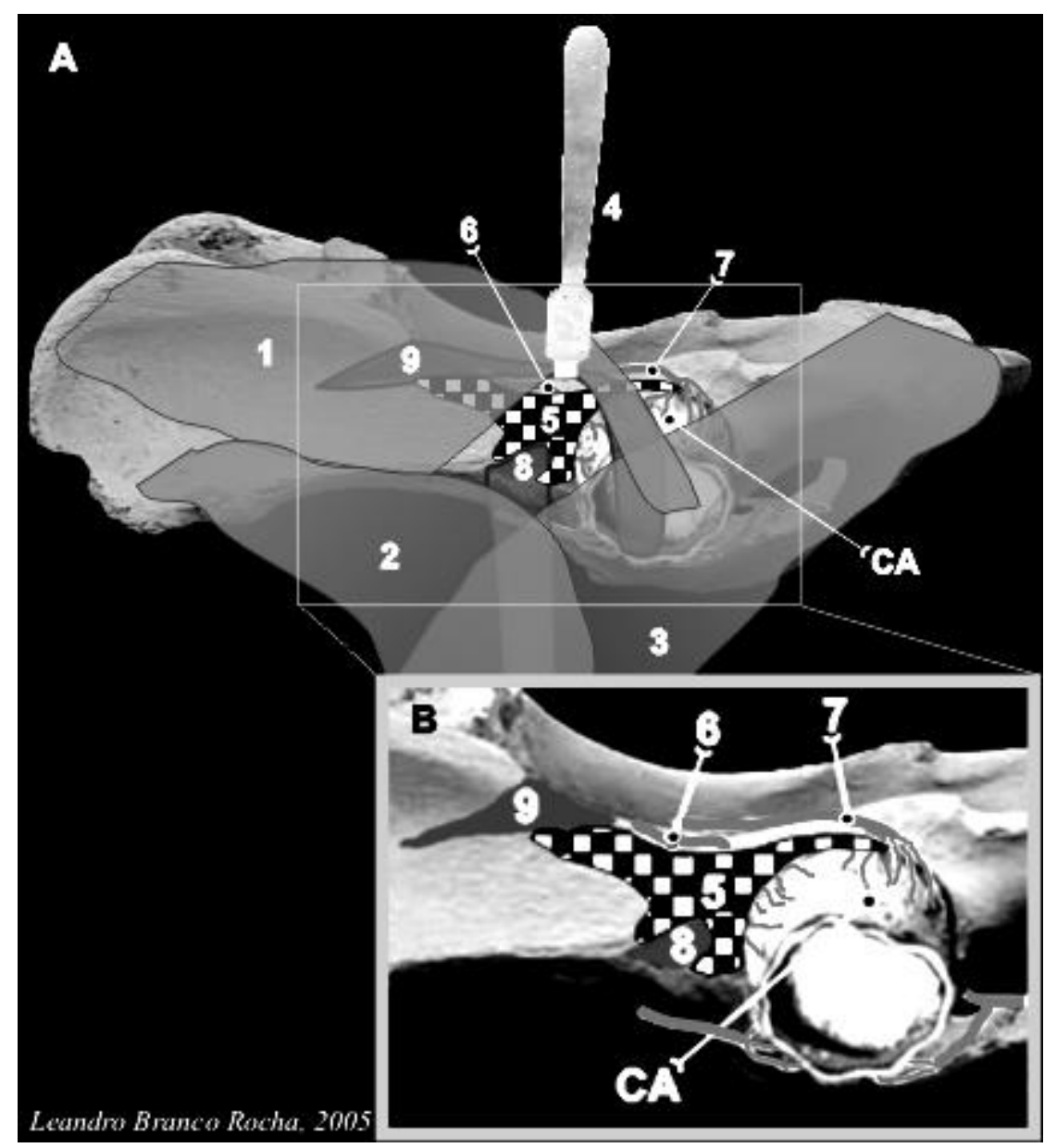

Figura 1: A - Abordagem cirúrgica para denervação da articulação coxofemoral em cães, A - realizada através do triângulo existente entre os músculos glúteo médio (1), tensor da fascia lata (2) e bíceps femoral (3). Retrator de Hohmann (4) elevando os músculos glúteos médio (1) e profundo (9) dorsalmente. B - Área de raspagem do periósteo (5 - xadrez) eliminando os ramos do nervo glúteo cranial (6) e alguns ramos do nervo ciático (7), formando uma meia lua crânio-dorsal a cápsula articular (CA). A denervação estendendose ao redor das inserções dos músculos reto femoral (8) e glúteo profundo (9). Recife-PE, 2005.

\section{RESULTADOS E DISCUSSÃO}

Todos os cães, no período pré-operatório, apresentaram sinais de dor com graus variados, repercutindo na função articular.

No teste de estação bípede, verificou-se que, com 48 horas de pós-cirúrgico, apenas um cão (10\%) teve melhora da dor, oito (80\%) mantiveram-se estáveis e um (10\%) teve piora; com sete dias: seis cães (60\%) tiveram melhora da dor e quatro (40\%) mantiveram-se estáveis; com um mês, sete cães (70\%) tiveram melhora da dor e 3 (30\%) mantiveram-se estáveis; com dois meses, oito cães (80\%) tiveram melhora da dor e dois (20\%) mantiveram-se estáveis; com quatro e seis meses, sete cães $(70 \%)$ tiveram melhora da dor e três $(30 \%)$ retornaram ao estado pré-operatório, identificando-se que $70 \%$ dos animais que apresentavam esse teste positivo no pré-cirúrgico, a partir de dois meses, tornaram-se negativos.

$\mathrm{Na}$ avaliação da andadura, verificou-se que, com 48 horas, apenas um cão $(10 \%)$ teve melhora, oito $(80 \%)$ mantiveram-se estáveis e um $(10 \%)$ teve piora; com sete dias de pós-cirúrgico, cinco cães $(50 \%)$ tiveram melhora, quatro $(40 \%)$ mantiveram-se estáveis e um (10\%) teve piora; com um mês, seis cães $(60 \%)$ tiveram melhora e quatro (40\%) mantiveram-se estáveis; com dois meses, sete cães (70\%) tiveram melhora e três $(30 \%)$ mantiveram-se estáveis; com quatro meses, sete cães (70\%) tiveram melhora e três $(30 \%)$ retornaram ao estado préoperatório; com seis meses, oito (80\%) tiveram melhora e dois (20\%) mantiveram-se estáveis.

As graduações da dor desencadeada pelo teste de abdução com rotação externa, comparadas entre os tempos pré-operatório e pós-operatório, permitiram verificar que, após 48 horas, apenas três cães $(30 \%)$ tiveram melhora da dor e sete $(70 \%)$ 
mantiveram-se estáveis; com sete dias, seis cães (60\%) tiveram melhora da dor e quatro (40\%) mantiveram-se estáveis; com um mês, oito cães $(80 \%)$ tiveram melhora da dor, um (10\%) mantevese estável e um (10\%) retornou ao estado inicial; com dois meses, sete cães (70\%) tiveram melhora da dor, dois (20\%) voltaram ao estado inicial e um (10\%) manteve-se estável; com quatro meses, seis cães $(60 \%)$ tiveram melhora da dor e quatro $(40 \%)$ voltaram ao estado inicial; e com seis meses: oito cães (80\%) tiveram melhora da dor, um (10\%) manteve-se estável e um (10\%) voltou ao estado inicial.

As graduações da dor desencadeada pelo teste de iliopsoas, comparadas entre o tempo préoperatório e os tempos de avaliação pós-operatório, permitiram verificar que, após 48 horas, três cães (30\%) apresentaram melhora da dor e sete (70\%) mantiveram-se estáveis; com sete dias de póscirúrgico, sete cães $(70 \%)$ apresentaram melhora da dor, dois $(20 \%)$ mantiveram-se estáveis e um $(10 \%)$ voltou ao estado inicial; com um, dois, quatro e seis meses, os dez cães (100\%) apresentaram melhora da dor. Não ocorreram casos de piora da dor neste teste.

A aplicação do teste de Wilcoxon permitiu verificar que no teste de estação bípede e na avaliação da andadura, com 48 horas e sete dias não houve redução estatisticamente significante do grau de dor, mas, a partir de um mês, houve redução estatisticamente significante. No teste de abdução com rotação externa, verificou-se que houve redução estatisticamente significante da dor já partir do sétimo dia pós-cirúrgico. No teste de iliopsoas houve redução estatisticamente significante da dor em todos os tempos do pós-cirúrgico $(\mathrm{P}<0,01)$.

No decorrer dos retornos, com exceção do quarto mês, a média da graduação da dor diminuiu gradativamente (Figura 2) e as amplitudes de melhora da dor elevaram-se (Figura 3). No entanto, houve interferência nesses resultados pelos motivos expostos a seguir.

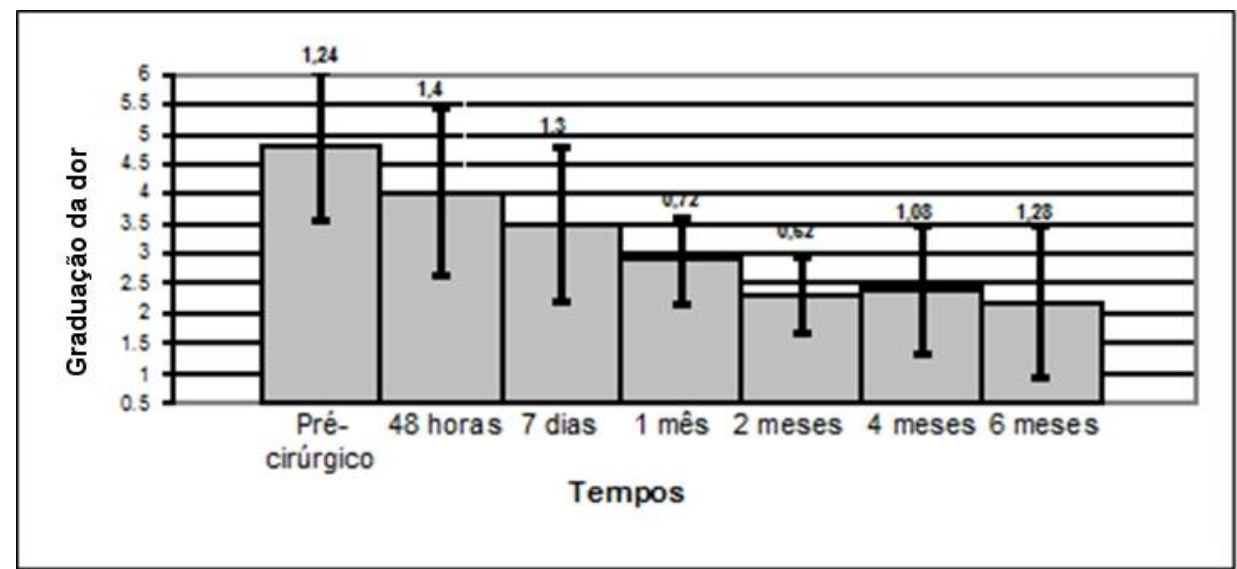

Figura 2: Média e desvio padrão das graduações da dor dos 10 animais submetidos à denervação coxofemoral, nos tempos pré e pós-cirúrgico. Recife-PE, 2005.

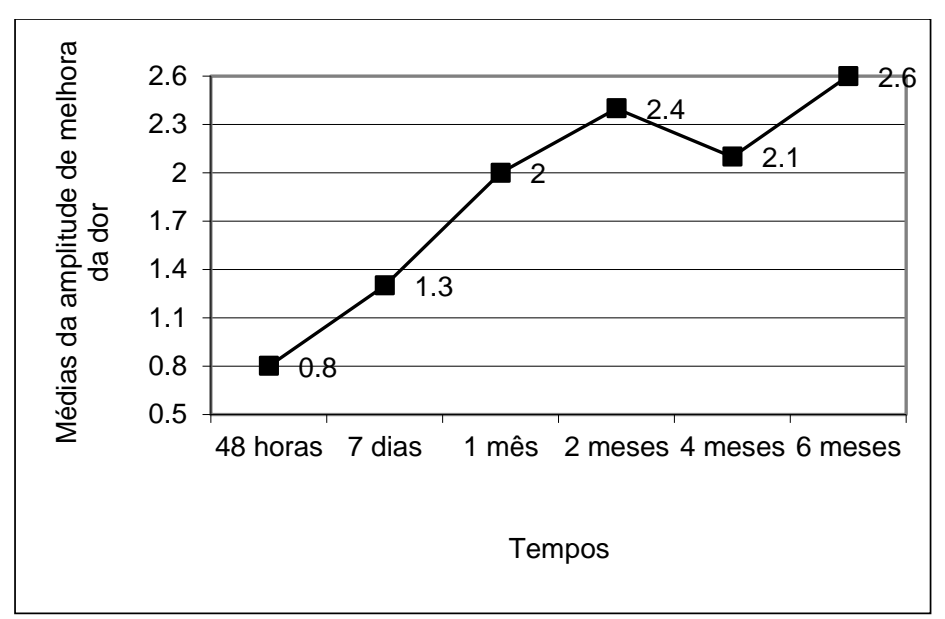

Figura 3: Médias da amplitude de melhora da dor (diferença de grau em relação ao do pré-operatório) nos tempos pós-operatório de avaliação. Recife-PE, 2005. 
A limitada redução da dor no teste de estação bípede e da claudicação na avaliação da andadura, nos períodos 48 horas e sete dias, foi compatível com os resultados revisados na literatura (KINZEL et al., 2002a). Sabe-se que, no local cirúrgico, assim como nos tecidos circunjacentes, a reatividade aos estímulos mecânicos fica aumentada, devido à ação de mediadores inflamatórios (PASCOE, 1998), e essa sensibilização piora com a ação mecânica da cabeça do fêmur instável.

O animal 1, no retorno de 48 horas, apresentou dor intensa no membro pélvico esquerdo, sendo diagnosticada luxação coxofemoral crâniodorsal pós-cirúrgica. Isso ocorreu porque logo após a cirurgia houve um alívio da dor na cápsula articular, fazendo com que o animal apoiasse este membro com mais firmeza, desenvolvendo mais atividades físicas, incluindo correr, o que, junto à atrofia muscular pré-existente, contribuiu para a luxação. Surpreendentemente, a partir do retorno de sete dias, o animal apresentou progressiva melhora da dor, encontrando-se aos dois meses com grau mínimo de dor. Para evitar o ocorrido, os seguintes cães operados foram submetidos a repouso em canil por sete dias e retorno gradual às atividades, o que contribuiu para evitar a ocorrência de luxação nos demais cães.

A piora dos sinais clínicos dos cães 7 e 10 no teste de estação bípede ocorreu devido à concomitante existência de dor na coluna vertebral lombo-sacral, diagnosticada já no período préoperatório, que pode ter se exacerbado pelo aumento da movimentação pós-operatória gerada pela denervação coxofemoral. Afecções que acometem a coluna lombo-sacral fazem parte do diagnóstico diferencial da displasia coxofemoral, sendo assim, animais displásicos devem ser submetidos a um exame ortopédico e neurológico detalhado (LECOUTEUR \& CHILD, 1997). Mesmo com outra afecção, esses animais foram beneficiados com melhora da andadura, refletida na satisfação dos proprietários.

Cães displásicos com idade avançada e intensa fibrose na cápsula articular apresentam normalmente resultado positivo no teste de estação bípede (NOGUEIRA \& TUDURY, 2002). Dos cães nessa situação (três cães) apenas o número 3 não apresentou melhora nesse teste.

No quarto mês, o retorno da claudicação do cão 4 ocorreu devido ao estado de pseudociese que causa como sintomatologia fraqueza, letargia e comportamento anormal (ETTINGER \& BARRETT, 1997). O proprietário relatou que, quando o animal saia de debaixo da cama, apresentava claudicação, que cessou quando houve interrupção desse comportamento, levando a crer que o posicionamento sob o móvel de alguma forma promoveu uma sobrecarga mecânica em um dos outros locais de origem da dor na displasia (GARDNER, 1950; HAMLET et al., 1972; ARNOCZKY \& MARSHALL, 1981 e MORGAN, 1997).

Apesar da tendência crescente, as baixas médias da amplitude de melhora da claudicação na avaliação da andadura (Figura 4) ocorreram porque essa avaliação também sofreu influências: da luxação pós-cirúrgica do animal 1 , da dor lombo-sacral préexistente nos animais 7 e 10 e da ausência de claudicação do animal $8 \mathrm{em}$ todos os tempos.

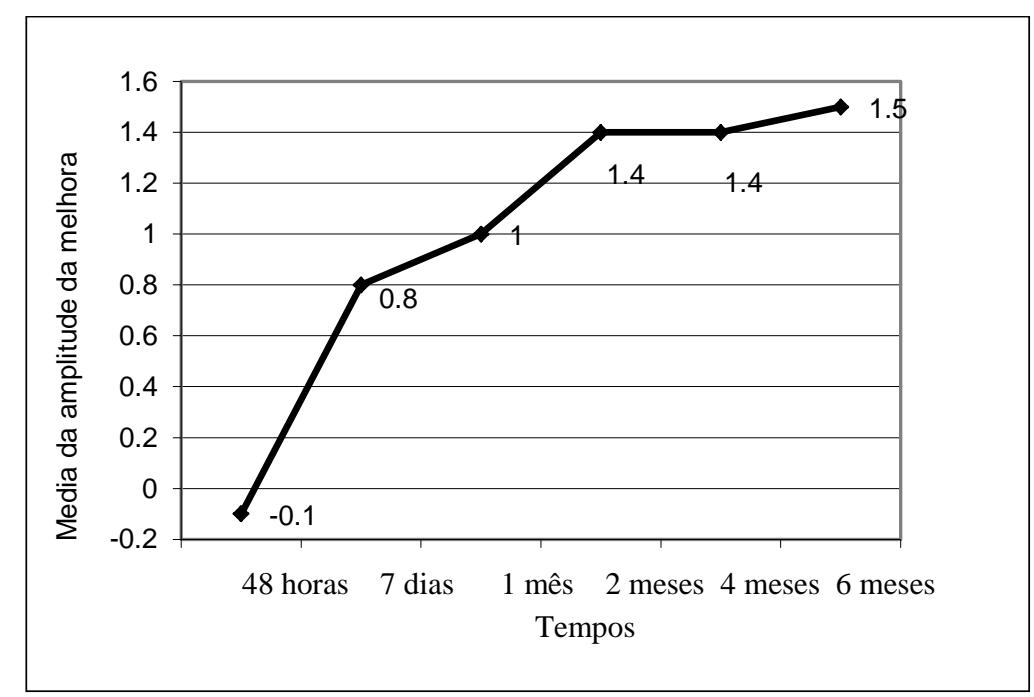

Figura 4: Médias da amplitude de melhora da claudicação (diferença de grau em relação ao do préoperatório) nos tempos pós-operatórios de avaliação. Recife-PE, 2005. 
BRAUN et al.(2003), durante um período médio de avaliação de três anos e quatro meses, tiveram como resultado a ausência de dor durante a rotação, flexão e extensão da articulação em $61,5 \%$ de 26 cães; no entanto, neste estudo, com seis meses foi verificada a ausência de dor no teste de abdução com rotação externa em apenas 1 cão $(10 \%)$.

Comparativamente aos outros testes, as médias das graduações do teste de abdução com rotação externa foram maiores (Figura 5), apesar de apresentarem uma tendência a crescer e as médias das amplitudes da melhora da graduação terem sido baixas (Figura 6), provavelmente pelo fato de que esse teste provoca distensão de outras áreas da cápsula articular (região dorso-caudal) (NOGUEIRA \& TUDURY, 2002), não passíveis de denervação pela abordagem executada (GASSE et al., 1996).

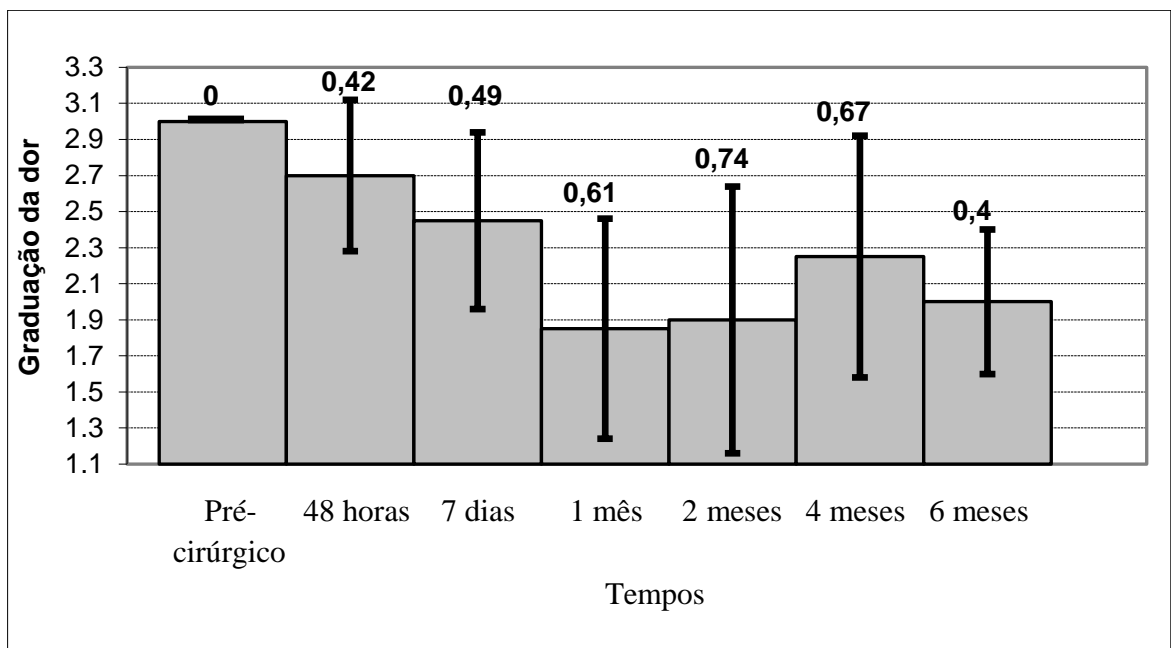

Figura 5: Média e desvio padrão das graduações da dor no teste de abdução com rotação externa dos 10 animais submetidos à denervação coxofemoral, nos tempos pré e pós-cirúrgico. Recife-PE, 2005.

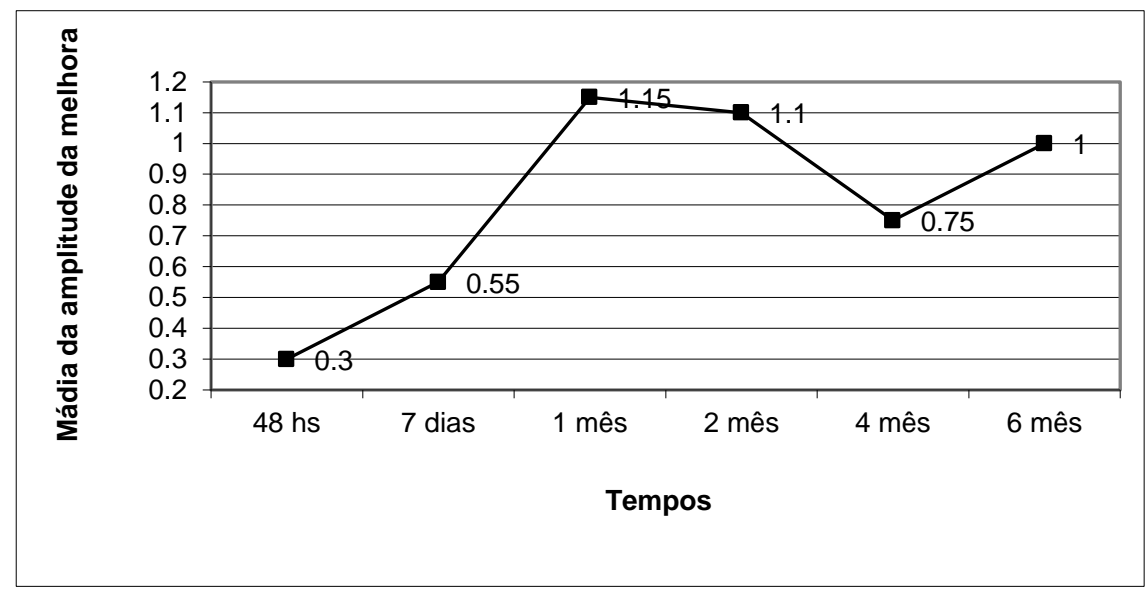

Figura 6: Médias da amplitude de melhora da dor no teste de abdução com rotação externa (diferença de grau em relação ao do pré-operatório) nos tempos pós-operatórios de avaliação. Recife-PE, 2005.

As médias da dor no teste de iliopsoas também tiveram tendência a diminuir durante os retornos pós-cirúrgicos (Figura 7). Comparativamente aos resultados dos outros testes, este permitiu verificar uma maior média da amplitude de melhora da dor nos tempos pós- cirúrgicos (Figura 8). Sabe-se que a contratura da musculatura adutora periarticular coxofemoral provoca processos neuroirritativos nas inserções dos músculos, causando dor (HAMLET et al., 1972; ARNOCZKY \& MARSHALL, 1981; BANKS, 1992; GASSE et al., 1996; MORGAN, 1997; 
PIERMATTEI \& FLO, 1999; ALVAREZ, 2001; KINZEL et al., 2002b). Sendo assim, o alívio da dor na cápsula articular fez com que ocorresse um alívio da tensão dos músculos adutores, consequentemente aliviando o processo neuroirritativo nas inserções destes.

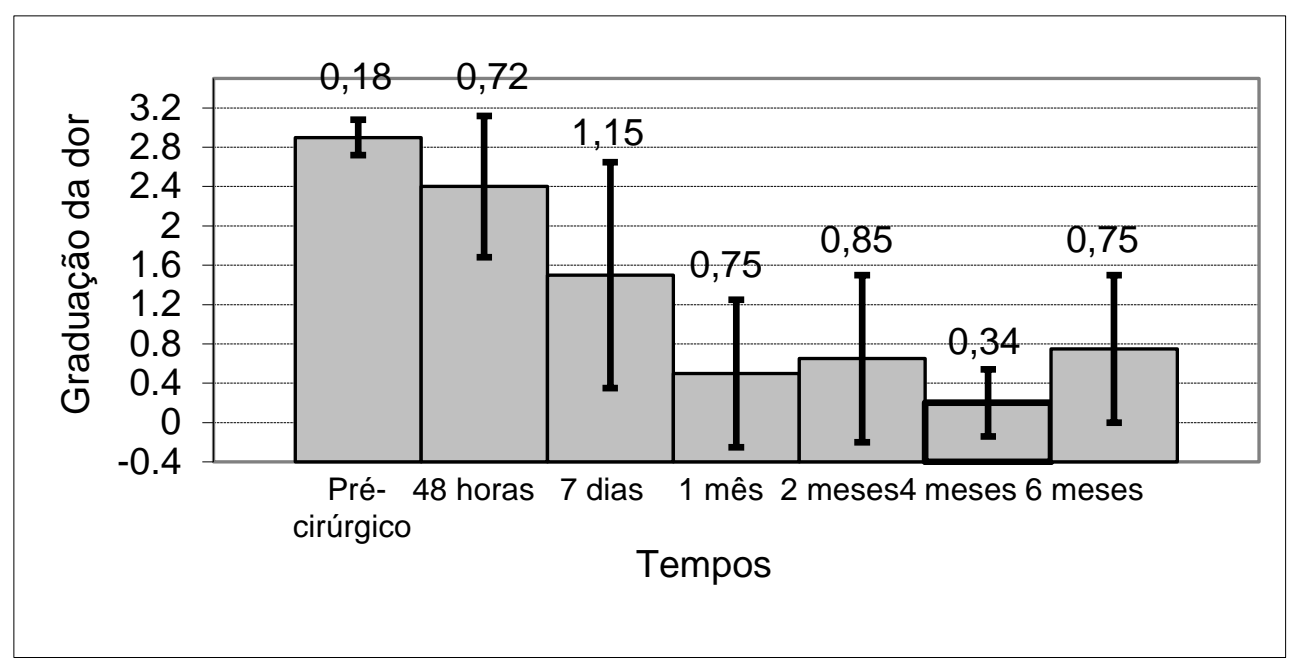

Figura 7: Média e desvio padrão das graduações da dor no teste de iliopsoas dos 10 animais submetidos à denervação coxofemoral, nos tempos pré e pós-cirúrgico. Recife-PE, 2005.

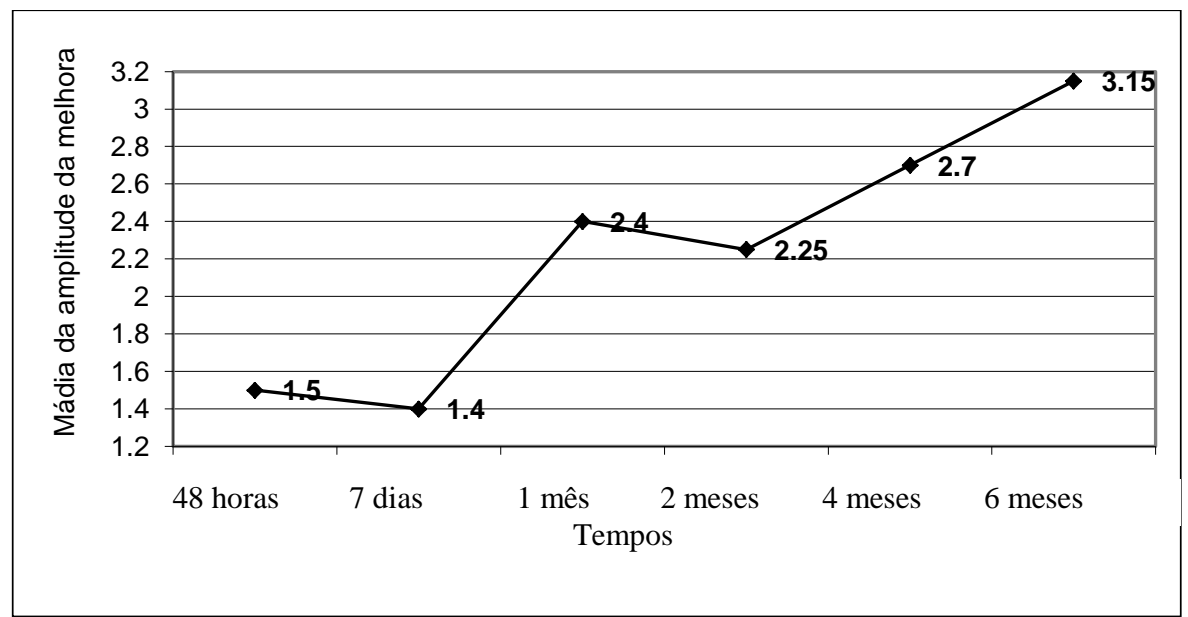

Figura 8: Médias da amplitude de melhora da dor no teste de iliopsoas (diferença de grau em relação ao do pré-operatório) nos tempos pós-operatório de avaliação. Recife-PE, 2005.

As recidivas da dor podem ocorrer após a denervação (BRAUN et al., 2003). Os resultados aqui apresentados mostram a importância de determinar exatamente a origem dessa dor na recidiva, pois outras origens da dor provocaram interferências na intensidade nas tendências de melhora.

$\mathrm{Na}$ avaliação de seis meses, verificou-se maior negatividade dos sinais de dor na avaliação da andadura (80\%) e teste de estação bípede $(70 \%)$ do que nos testes mais específicos de abdução com rotação externa $(10 \%)$ e de iliopsoas $(50 \%)$. Em suma, a avaliação funcional (andadura e estação bípede) foi mais condizente com a melhora clínica e a satisfação dos proprietários do que a avaliação em decúbito com testes ortopédicos específicos.

$\mathrm{Na}$ avaliação visual pré-cirúrgica da musculatura da coxa e pelve, nove cães (90\%) apresentavam atrofia muscular, exceto o animal 8 . Quando o animal displásico convive muito tempo com a dor, a musculatura da região pélvica e da coxa normalmente está atrofiada, principalmente os músculos glúteos e quadríceps (THOMAS, 1992; RISER, 1993; SOMMER \& FRATOCCHI, 1998; PIERMATTEI \& FLO, 1999; NOGUEIRA e TUDURY, 2002).

A aplicação do teste de Wilcoxon permitiu verificar que houve aumento estatisticamente 
significante da circunferência da coxa (massa muscular) $(\mathrm{P}>0,05)$, a partir do sétimo dia póscirúrgico, quando seis cães (60\%) já apresentaram aumento da massa muscular com elevação da média da circunferência da coxa de $35,8 \mathrm{~cm}$ para $37,3 \mathrm{~cm}$. Aos seis meses, sete cães $(70 \%)$ apresentaram melhora da circunferência de uma média de $37 \mathrm{~cm}$ (pré-cirúrgico) para $40 \mathrm{~cm}$.

$\mathrm{O}$ animal 1, mesmo sofrendo luxação coxofemoral no membro pélvico esquerdo, demonstrou melhora gradativa da atrofia muscular, mais lenta que a do membro direito, de forma que, aos seis meses, os dois membros apresentavam a mesma massa muscular de aparência normal.

Na literatura, é citada a importância de que um programa de exercícios seja introduzido de forma gradual e progressiva, respeitando as limitações dos animais com osteoartrose (MILLIS \& LEVINE, 1997; COOK, 2003). Uma restrição inicial e parcial de exercícios deve ser recomendada com rigor aos cães displásicos submetidos à denervação para evitar a luxação. Provavelmente, o grau de atrofia muscular e a distensão das estruturas de suporte provocam fragilidade que susceptibiliza à luxação.

Os animais 2, 5, 6 e 10, apesar de terem apresentado aumento da circunferência da coxa, tiveram influência do fato de estarem em crescimento; no entanto, na opinião do proprietário e visualmente no exame clínico pelo veterinário, os animais 2,5 e 6 apresentaram melhora da atrofia muscular. A Figura 9 mostra o aumento crescente estável das médias das circunferências das coxas nos animais entre seis meses a um ano e quatro meses. Já nos animais com mais de cinco anos não houve tendência de elevação desses valores no decorrer dos tempos. Isso confirma que os melhores resultados da reabilitação muscular ocorrem nos animais mais jovens (BRAUN et al., 2003).

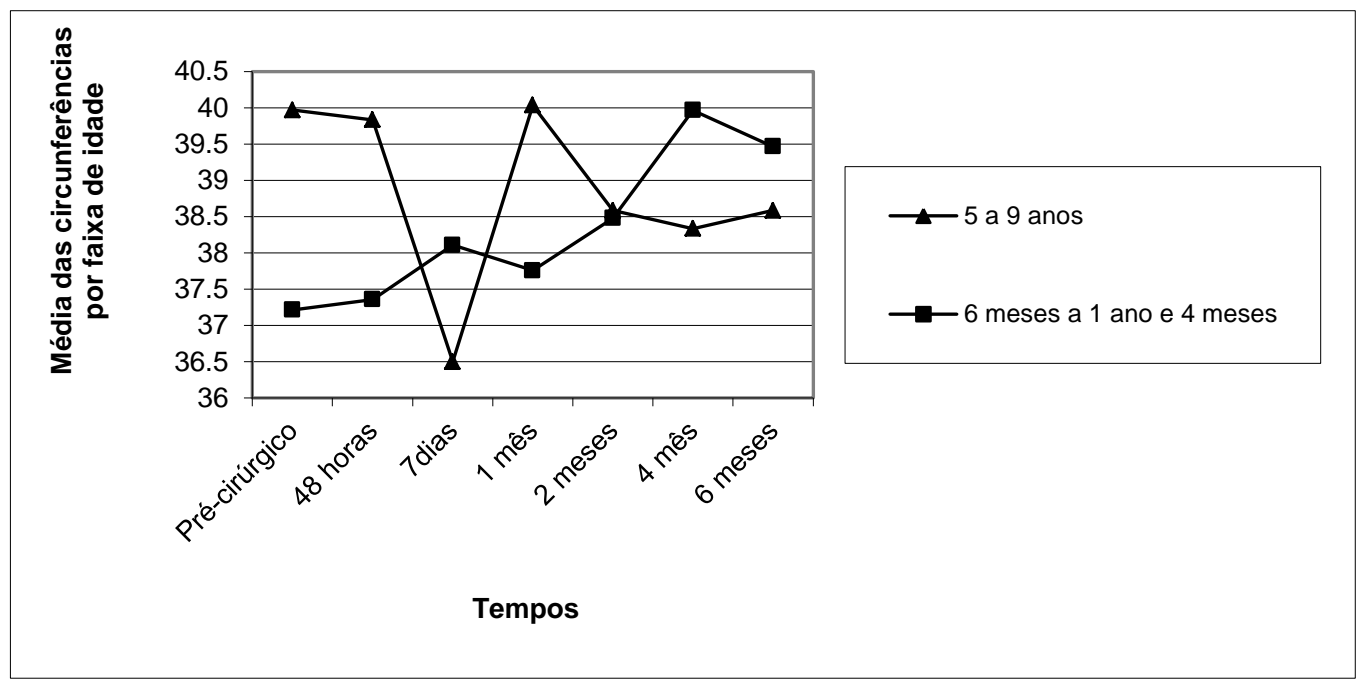

Figura 9: Médias das circunferências das coxas por faixa de idade. Recife-PE, 2005.

Dos animais com dor lombo-sacral, o número 10 apresentou surpreendente melhora da média da massa muscular de $36 \mathrm{~cm}$ no pré-cirúrgico para $40 \mathrm{~cm}$ aos seis meses, já o cão 7 apresentou períodos de melhora temporária aos quatro meses, voltando a atrofiar aos seis meses.

Sabe-se que alguns animais suportam bastante a dor e outros respondem exageradamente a um estímulo mínimo (AIGÉ \& CRUZ, 2001). Isso foi verificado no animal 8 , o qual mesmo apresentando positividade nos testes de rotação com abdução externa e iliopsoas, apresentou negatividade na avaliação da andadura e teste de estação bípede, o que condizia com os relatos do proprietário de que, mesmo no pré-cirúrgico, o animal não demonstrava grandes dificuldades em suas atividades, favorecendo a normalidade da massa muscular.

À medida que os proprietários observavam a melhora das atividades, os mesmos, por conta própria, estimulavam seus animais a exercitar-se, favorecendo a reabilitação muscular. No entanto, o animal 3 não recebeu esse estimulo, fazendo com que a vida sedentária causasse piora da atrofia muscular.

Apesar de os resultados serem influenciados pelos fatores expostos, houve uma tendência ao aumento da massa muscular após o alívio da dor na cápsula articular em consequência aos efeitos causados pela denervação (Figura 10). 


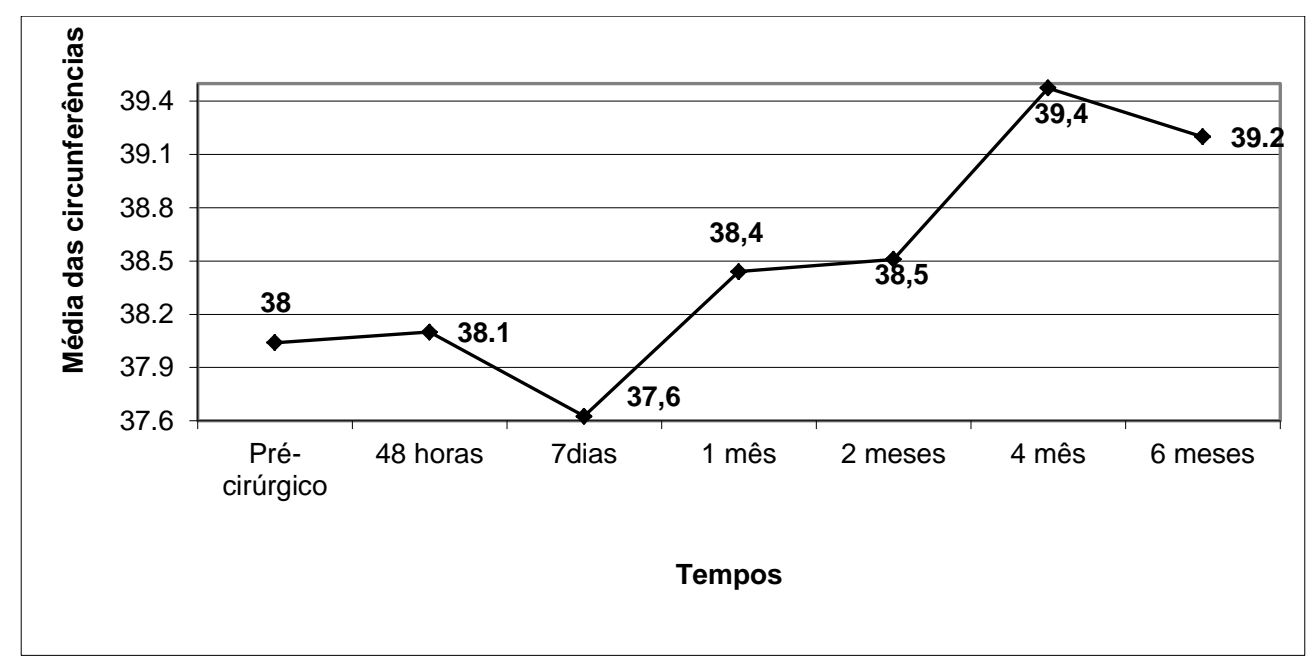

Figura 10: Médias das circunferências das coxas dos animais nos tempos pré-operatório e pós-operatório. Recife-PE, 2005.

Sabe-se que exercícios físicos controlados de baixo impacto ajudam a manter uma massa muscular adequada; auxiliam na perda de peso, diminuindo a carga de estresse na articulação; aumentam o ângulo de movimentação articular (HAAN \& BEALE, 1999; DASSLER, 2003) e diminuem a inflamação com consequentemente alívio da dor (MILLIS \& LEVINE, 1997; HARDIE, 2003). No entanto, para os animais deste trabalho, não foram prescritos exercícios específicos, sendo mantidas as atividades de costume impostas pelo proprietário em seu manejo pré-cirúrgico. Os animais beneficiados com a denervação coxofemoral demonstraram além da melhora imediata, uma melhora gradativa, provavelmente devido ao aumento da atividade física com seus consequentes benefícios em longo prazo.

Apesar de os resultados da reabilitação muscular terem sido discutidos aqui, torna-se importante comprovar esses resultados em futuros trabalhos, pois a maioria dos cães estudados eram jovens e o ganho de massa muscular pode ter ocorrido devido ao próprio crescimento de cada animal.

Para se manter uma estabilidade articular, é necessário um volume muscular adequado (RISER \& SHIRER, 1967), entre outros fatores. Quanto menor o ID e maior o NorDis, mais próxima à cabeça do fêmur estará do acetábulo, proporcionando uma maior estabilidade articular (ADAMS et al., 1998). Os cães displásicos submetidos à denervação coxofemoral foram beneficiados (como evidenciado pelo teste de Wilcoxon) com redução estatisticamente significante do ID e aumento do NorDis $(\mathrm{P}<0,01)$, em que, de 20 articulações denervadas, 18 (90\%) tiveram redução do ID e 16 (80\%) tiveram aumento do NorDis. As Figuras 11 e 12 mostram as tendências de redução e aumento das médias do ID e NorDis respectivamente.

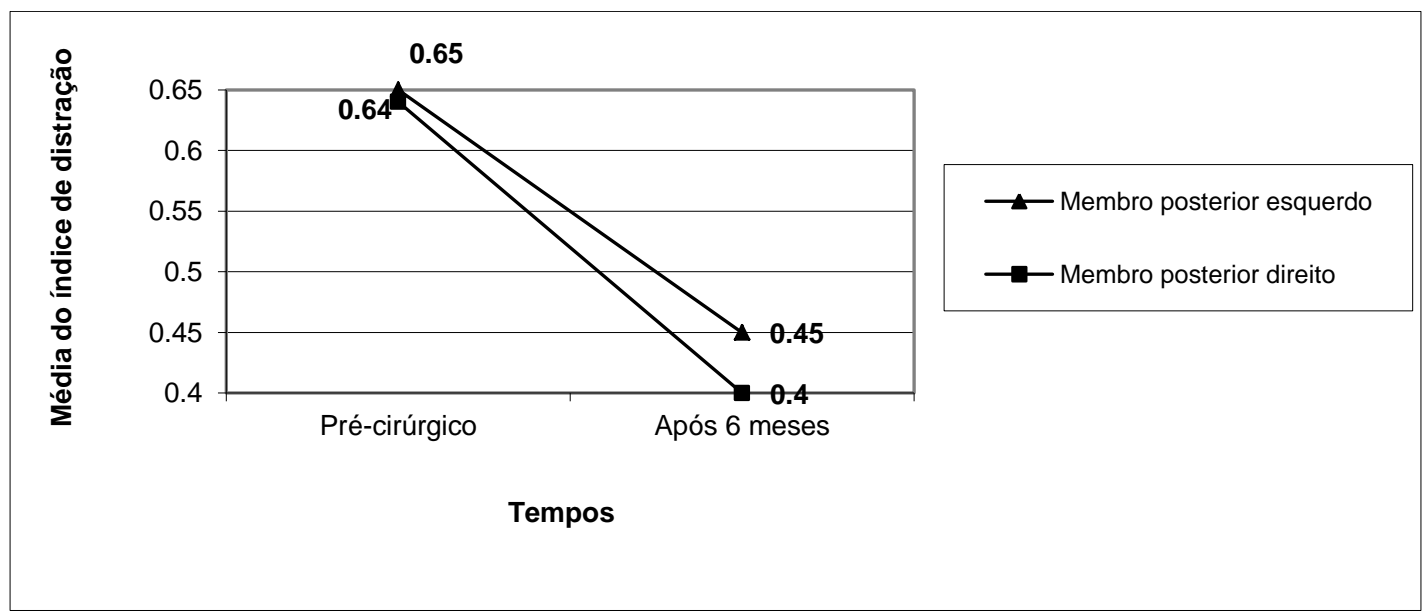

Figura 11: Médias do ID nos tempos pré-cirúrgico e após seis meses. Recife-PE, 2005. 


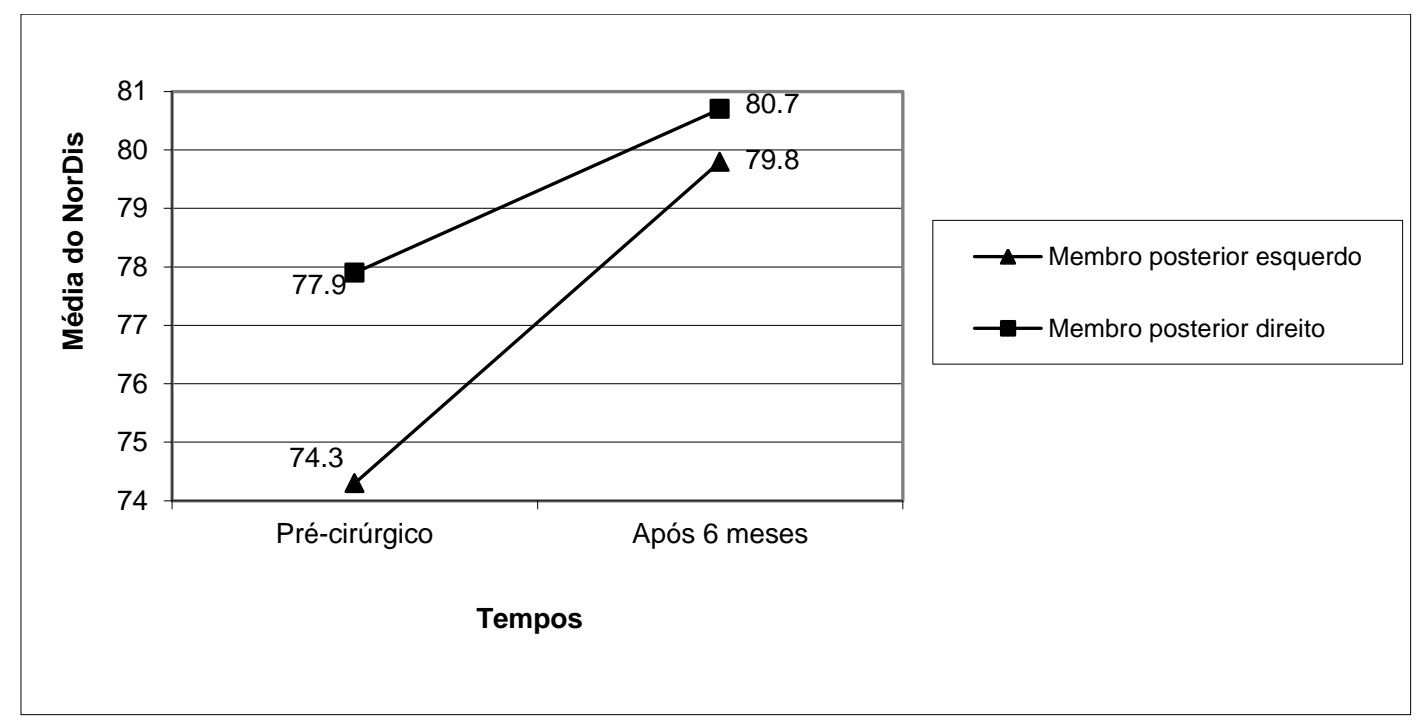

Figura 12: Médias do NorDis nos tempos pré-cirúrgico e após seis meses. Recife-PE, 2005.

A reabilitação muscular com consequente melhora da estabilidade articular, proporcionada pela denervação coxofemoral, já havia sido postulado na literatura (KÜPPER \& KINZEL, 1994; KINZEL \& KÜPPER, 1997; KINZEL et al., 2002a, b; BRAUN et al., 2003; FERRIGNO et al., 2007a), sendo que os resultados radiográficos deste trabalho a confirmam.

Apesar de estar sendo demonstrado em valores matemáticos (ID e NorDis), a diminuição do espaço entre a cabeça do fêmur e o acetábulo foi facilmente observada, mesmo sem a medição desses índices, como mostra a Figura 13.

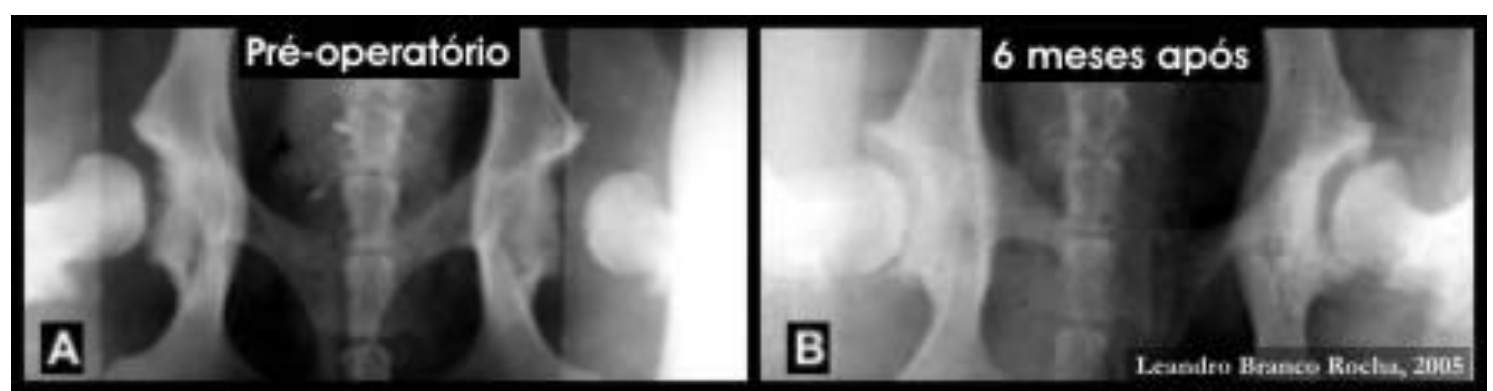

Figura 13: Imagem radiográfica das articulações coxofemorais do cão 7 pelo método PennHip ${ }^{\circledR}$, para determinação do ID e NorDis. Observa-se, seis meses após a denervação, visível diminuição do espaço entre as cabeças femorais e acetábulos, com maior cobertura das cabeças femorais pelos acetábulos. Recife-PE, 2005.

A lassidão da articulação coxofemoral é simulada durante a avaliação do ID e NorDis, semelhante à posição das estruturas ósseas coxofemorais durante a sustentação de peso (NOGUEIRA et al., 2005). Sendo assim, nos cães com diminuição do ID e aumento do NorDis ocorreu maior cobertura do acetábulo na cabeça do fêmur (SMITH et al., 1990) (Figura 13). Isso reflete, durante a sustentação de peso e deambulação, uma menor distensão da cápsula articular, com maior cobertura da cabeça do fêmur, diminuindo o estimulo sensitivo nas áreas da cápsula não possíveis de serem denervadas pela abordagem realizada. Provavelmente, esse fenômeno também esteve inter- relacionado com a melhora gradativa da dor, à medida que ocorreu a reabilitação muscular e estabilização articular.

$\mathrm{Na}$ avaliação radiográfica pré-cirúrgica, observou-se que os dez animais apresentaram sinais variados de DAD. Após seis meses, sete destes não apresentaram alterações radiográficas distintas em relação a avaliação pré-cirúrgica; no entanto, o animal 7 (Figura 13) teve um aumento de osteófitos nas bordas acetabulares, o animal 4 apresentou fratura de osteófito na borda acetabular cranial do membro pélvico direito e o animal 10 , uma maior remodelagem da cabeça do fêmur do membro pélvico esquerdo, sem haver diferença da melhora 
funcional em relação ao membro contralateral, em que não houve piora radiográfica da doença degenerativa, mas é preciso ressaltar que, muitas vezes, a gravidade dos achados radiográficos não é proporcional a dos achados clínicos (RISER, 1993; MARTINEZ, 1997). As lesões articulares causadas pela displasia e sua evolução permanecem inalteradas (KINZEL \& KÜPPER, 1997; KINZEL et al., 2002b). Isso foi confirmado pela não observação de melhora na apresentação radiográfica nos 10 casos, o que já era de se esperar, pois se sabe que nenhum tratamento é efetivo em restaurar uma articulação displásica com DAD à normalidade (BIASI et al., 2000; COOK, 2003).

Em animais adultos com DAD severa, a avaliação da frouxidão geralmente não é confiável, pois o espessamento da cápsula articular, fibrose e osteófito periarticular fazem com que a cabeça do fêmur fique mais firme no acetábulo (CHALMAN \& BUTLER, 1985; PIERMATTEI e FLO, 1999), porém isso não interferiu nos resultados, porque a avaliação radiográfica da instabilidade foi comparada entre os próprios animais num intervalo de tempo pequeno (seis meses). Além disso, piora das alterações degenerativas foi observada apenas nos três animais citados.

Em estudos realizados por FERRIGNO et al. (2007b) e SELMI et al. (2009), avaliando cães submetidos à denervação, verificou-se que não há diferença nos escores de dor atribuídos por veterinário e pelos proprietários. Sendo assim, a avaliação do proprietário é importante na avaliação da dor, por que esses conhecem mais o comportamento diário do seu animal do que o veterinário.

No retorno de um mês, os proprietários relataram que, logo após o sétimo dia pós-cirúrgico, os animais apresentaram uma significante melhora, concordando assim com os resultados obtidos por KINZEL et al. (2002a) e FERRIGNO et al. (2007a).

Todos os proprietários relataram que seus cães, após denervação, começaram a ter atitudes que não conseguiam executar antes da cirurgia, como: permanecer por mais tempo em posição bípede e em posição quadrupedal, coçar o corpo com os membros posteriores, sentar e deitar com posicionamento não habitual dos membros e maior disposição para suas atividades, conforme foi observado por KÜPPER \& KINZEL (1994); KINZEL \& KÜPPER (1997); KINZEL et al. (2002a, b); BRAUN et al. (2003); FERRIGNO et al. (2007a), sendo que essas melhoras refletem em uma melhor qualidade de vida dos cães (HAAN \& BEALE, 1999; MINTO et al., 2012). Através da anamnese, comprovou-se também que os cães mais jovens (seis meses a um ano e quatro meses), apresentam essa melhora mais rapidamente do que os animais mais velhos (cinco a nove anos), correspondendo com a avaliação da massa muscular por faixa de idade mostrada na Figura 9 (BRAUN et al., 2003).

Os benefícios dos tratamentos não cirúrgicos, quando a displasia já esta avançada, normalmente são temporários (KÜPPER \& KINZEL， 1994; KINZEL \& KÜPPER, 1997; KINZEL et al., 2002a, b; BRAUN et al., 2003; FERRIGNO et al., 2007a). Os proprietários dos cães $3,4,8$ e 9 relataram que antes da denervação já haviam sido submetidos a diversos tratamentos medicamentosos, com recidivas de dor dentro de um período de seis meses. Após a denervação, esses mesmos proprietários assim como os donos dos demais cães afirmaram satisfação com os resultados durante o tempo de avaliação. Em nenhum animal houve a necessidade de tratamento medicamentoso durante o período de avaliação.

A simplicidade da técnica, levando em consideração o curto tempo cirúrgico (média de 45 minutos) e de convalescência, também foram motivo de satisfação dos proprietários (MINTO et al., 2012).

\section{CONCLUSÃO}

A técnica de denervação coxofemoral em cães displásicos com doença articular degenerativa é eficaz no alívio da dor e, consequentemente, promove uma melhora da função articular. A reabilitação muscular após a melhora na capacidade de exercitar-se diminui o ID e aumenta o NorDis, ou seja, reduz a instabilidade. A melhora da qualidade de vida dos pacientes é motivo de satisfação dos proprietários.

\section{AGRADECIMENTOS}

À CAPES pela bolsa de mestrado e ao CNPq pela bolsa de PIBIC.

\section{REFERÊNCIAS}

ADAMS, W.M.; DUELAND, R.T.; MEINEN, J.; O'BRIEN, R.T.; GIULIANO, E.; NORDHEIM, E.V. Early detection of canine hip dysplasia: comparison of two palpation and five radiographic methods. Journal of the American Animal Hospital Association, Lakewood, v.34, p. 339-347, 1998.

ANDERSON, A. Treatment of hip dysplasia. Journal of Small Animal Practice, v. 52, p. 182-189, 2011.

AIGÉ, V.; CRUZ, J.I. El dolor en los pequeños animales: bases neuroanatómicas, reconocimiento y tratamento. Consulta Difusión Veterinaria, v.9, n. 78, p. 63-70, 2001.

Ci. Anim. Bras., Goiânia, v.14, n.1, p. 120-134, jan./mar. 2013 
ALVAREZ, M.V. Actualización sobre displasia de cadera em el perro (parte 1). Revista del Colégio de Veterinários de la Província. Boletin Veterinário, Ano 6, n.22, p.67-72, dic. 2001.

ARAUJO, R. B.; REZENDE, C. M. F.; FERREIRA NETO, J. M.; MUZZI, L. A. L. Frequência da displasia coxofemoral em cães da raça Fila Brasileiro. Arquivo Brasileiro de Medicina Veterinária e Zootecnia, v.49, n.3, p.379-383, 1997.

ARNOCZKY, S.P.; MARSHALL, J.L. Degenerative joint disease. In: BOJRAB, M.J. Pathophysiology in small animal surgery, Philadelphia: Lea e Febiger, 1981. cap. 63 , p. 571-578.

BANKS, W.J. Sistema músculo-esquelético. In:

Histologia veterinária aplicada, 2. ed. São Paulo: Manole. 1992. cap. 16, p. 289-317.

BIASI, F.; MOTTA, T.; BERGAMO, F.M.M. Afecções ortopédicas da cães e gatos em crescimento - parte 3. Cães e Gatos: Revista do Clínico, v. 15, n.95, p.16-25, nov/dez, 2000 .

BRAUN， D.; LAUTERSACK， O.; SCHIIMKE， E. Dorsale denervation der hüftgelenkskapsel beim hund ergebnisse einer langzeitstudie. Kleintierpraxis, v. 4, p. 185-244, 2003.

CHALMAN, J.A.; BUTLER, H.C. Coxofemoral joint laxity and the Ortolani sign. Journal of the American Animal Hospital Association, v. 21, p. 671-676, 1985.

COOK, J.L. Preventative surgeries for canine hip dysplasia. Proceedings of the North American Veterinary Conference - Small Animal Edition, v. 17, p. 732-733, 2003.

DASSLER, C.L. Canine hip dysplasia: diagnosis and nonsurgical treatment. In: SLATTER, D. Textbook of small animal surgery, 3 ed. Philadelphia: Suanders, 2003. v. 2, cap. 144, p.2019-2029.

ETTINGER, S.J.; BARRETT, K.A. Fraqueza e síncope. In: ETTINGER, S.J., FELDMAN, E.C. Tratado de medicina interna veterinária, 4 ed. São Paulo: Manole, 1997 , v. 1 , cap. 11 , p. 64-74.

FERRIGNO, C.R.A.; SCHMAEDECKE, A.; FERRAZ, V.C.M. Abordagem cirúrgica inédita para denervação acetabular em cães. Pesquisa Veterinária Brasileira, v.27, n.2, p. 61-63, 2007a.

FERRIGNO, C.R.A.; SCHMAEDECKE, A.; OLIVEIRA, L. M.; D’ÁVILA, R. S.; YAMAMOTO, E.Y.; SAUT, J.P.E. Denervação acetabular cranial e dorsal no tratamento da displasia coxofemoral em cães: 360 dias de evolução de 97 casos. Pesquisa Veterinária Brasileira, v.27, n.8, p. 333-340, agosto 2007b.

GARDNER, E. Physiology of movable joint. Physiological Reviews, v. 30, n.2, p. 127- 168, Apr. 1950.

GASSE H.; ENGELKE E.; WAIBL H. Zur innervation der hüftgelenkkapsel beim hund. Kleintierpraxis, v.41. p.883-886. 1996.
HAAN, J.J. BEALE, B.S. Sistema esquelético In: GOLDSTON, R.T. e HOSKINS, J.D. Geriatria e gerontologia do cão e gato, São Paulo: Roca. 1999. cap.17, p.391-419.

HAMLET A.; PETERSON, M.D.; WINKELMANN, M.D.; MARK, B.; COVENTRY, M.D. Nerve endings the hip joint of the cat: Their morphology, distribution, and density. Journal of Bone and Joint Surgery, v. 54-A, n.2, p.333-343, Mar. 1972.

HARDIE, E.M. Managing chronic pain in dogs: the next level. Proceedings of the North American Veterinary Conference - Small Animal Edition, v. 17, p. 7777-7778, 2003.

KINZEL, S,; HEIN, S,; SCHEVEN, C,; KÜPPER, W. 10 years experience with denervation of the hip joint capsule for treatment of canine hip dysplasia and arthrosis. Berliner und Munchener Tierarztliche Wochenschrift, v. 115, n.1-2, p. 53-56, 2002 b.

KINZEL, S.; SCHEVEN, C.; BUECKER, A.; STOPINSKI, T.; KUPPER, W. Clinical evaluation of denervation of the canine hip joint capsule: a retrospective study of 117 dogs. Veterinary and Comparative Orthopedics and Traumatology, Stuttgart, v. 15, p.5156, 2002 a.

KINZEL, S.; FASSELT, R.; PRESCHER, A.; SELZER, C.; GRAF VON KEYSERLINGK, D.; KÜPPER, W. Sensory innervation of the hip joint capsule in dogs. Tierarztliche Praxis, v.26, n.5, p.330-335, 1998.

KINZEL, S.; KÜPPER, W. Surgical technique and clinical experiences with hip joint denervation in the dog. Der Praktische Tierarzt, v.27, p. 26-29, 1997.

KÜPPER, W.; KINZEL, S. Denervation der Hüftgelenkkapsel. Tagugsberichte. Therapie von Hüftkhankheiten, dvg-Tagung, Weisloch, p. 19-21, 1994.

LECOUTEUR, R.A.; CHILD, G. Afecções da medula espinhal. In: ETTINGER, S.J., FELDMAN, E.C. Tratado de medicina interna veterinária, 4 ed. São Paulo: Manole, 1997. vol. 1, cap. 83, p. 890-980.

MARTINEZ, S.A. Congenital condition that lead to osteoarthritis in the dog. The Veterinary Clinics of North America. Small Animal Practice, Philadelphia, v.27. n.4. p.735-758, 1997.

MAY, S.A. Degenerative joint disease (osteoarthritis, osteoarthrosis, secondary joint disease). In: HOULTON, J.E.F.; COLLINSON, R.W. Manual of small animal arthrology, 1994. cap.5. p.62-74.

MILLIS, D.L.; LEVINE, D. The role of exercise and physical modalities in the treatment of osteoarthritis. Veterinary Clinics of North America: Small Animal Practice, v. 27, n. 4, p. 913-930, 1997.

MINTO, B.W.; SOUZA,V.L.; BRANDÃO, C.V.S.; MORI, E.S.; MORISHIN FILHO, M.M.; RANZANI, J.J.T. Avaliação clínica da denervação acetabular em cães com displasia coxofemoral atendidos no Hospital 
Veterinário da FMVZ - Botucatu - SP. Veterinária e Zootecnia, v.19, n.1, p. 91-98, 2012.

MORGAN, S.J. Pathologic alterations in canine hip dysplasia. Journal of the American Veterinary Medical Association, Philadelphia, v. 210, n. 10, p. 1446-1450, May 15, 1997.

NOGUEIRA, S.R.; ROCHA, L. B.; TUDURY, E. A. Utilização do índice de distração no diagnóstico da displasia coxofemoral canina. Clínica Veterinária, São Paulo, n. 54, p. 28-42, jan/fev, 2005.

NOGUEIRA, S.R.; TUDURY, E.A., Exame clínico ortopédico em cães e gatos - part 1. Clínica Veterinária, São Paulo, n.36, p. 34-58, jan/fev, 2002.

PASCOE, P.J. Cuidados pós-operatórios do paciente. In: SLATTER,D. Manual de cirurgia de pequenos animais 2 ed. São Paulo: Manole,1998, v. 1, cap. 22, p. 287-299.

PIERMATTEI, D.L.; FLO, G.L. A articulação coxofemural. In: Ortopedia e tratamento das fraturas dos pequenos animais, São Paulo: Manole. 1999, cap.15, p.394-436.

REIS, J.C. Estatística aplicada à pesquisa em ciência veterinária, 1 ed. Olinda: Luci Artes Gráficas, 2003, $651 \mathrm{p}$.

RISER, W.H. Canine hip dysplasia. In: BOJRAB, M.J.; SMEAK,D.D.; BLOOMBERG, M.S. Disease mechanisms in small animal surgery, 2 ed. Philadelphia: Lea e Febiger, 1993. cap.112, p. 799-803.

RISER, W.H.; SHIRER, J.F. Correlation between canine hip dysplasia and pelvic muscle mass: a study of 95 dogs. American Journal of Veterinary Research, Chicago, v.28, n. 124, p. 869-777, 1967.

SELMI, A. L.; PENTEADO, B. M.; LINS, B. T. Denervação capsular percutânea no tratamento da displasia coxofemoral canina. Ciência Rural, Santa Maria, v.39, n.2, p.460-466, mar-abr, 2009.

SILVA, G. F.; CARVALHO, A.V.; PENTEADO, B. M.; LINS, B. T.; SELMI, A. L. Desnervação capsular percutânea ou aberta no tratamento da dor na displasia coxofemoral canina. Ciência Rural, v.42, n.4, p.685-690, abr, 2012.

SMITH, G.K.; BIERY, D.N.; GREGOR, T.P. New concepts of coxofemoral joint stability and the development of a clinical stress-radiographic method for quantitating hip joint laxuty in the dog. Journal of the American Veterinary Medical Association, v.196, n. 1, p. 59-70, 1990.

SOMMER, E.L.; FRATOCCHI, C.L.G. Displasia coxofemoral canina. Revista de Educação Continuada do CRMV-SP, v.1, p.36-43, 1998.

THOMAS, R.; CLARCK, D.M. Canine hip dysplasia: clinical signs and physical diagnosis. The Veterinary Clinics of North America. Small Animal Practice, Canine Hip Dysplasia, v.22, n.3, p.551-558, 1992.

TORRES, R.C.S.; FERREIRA, P.M.; SILVA, D.C. Frequência e assimetria da displasia coxofemoral em cães Pastor-Alemão. Arquivo Brasileiro de Medicina Veterinária e Zootecnia, v.51, n.2, p.153-156, 1999.

WENDELBURG, K.L. Disordens of the hip joint in the canine athlete. In: BLOOMBERG, M.S.; DEE, J.F.; TAYLOR, R.A. Canine sports medicine and surgery, Philadelphia: Saunders, 1998, chap. 22, p. 174-195. 